\title{
Managing Tax Complexity: The State of Play after Henry ${ }^{\dagger}$
}

\author{
Binh Tran-Nam, ${ }^{1,2}$ Chris Evans, ${ }^{1,3}$ Richard Krever ${ }^{4}$ and Philip Lignier ${ }^{5}$ \\ ${ }^{1}$ School of Taxation and Business Law, UNSW Business School, UNSW Australia, Sydney, NSW, Australia. \\ ${ }^{2}$ RMIT Asia Graduate Centre, RMIT University Vietnam, Ho Chi Minh City, Vietnam. \\ ${ }^{3}$ Department of Taxation, Faculty of Economic and Management Sciences, University of Pretoria, Pretoria, \\ South Africa.
}

${ }^{4}$ Department of Business Law and Taxation, Monash Business School, Monash University, Melbourne, VIC, Australia.

${ }^{5}$ Tasmanian School of Business and Economics, University of Tasmania, Launceston, TAS, Australia.

*Correspondence: Binh Tran-Nam, School of Taxation and Business Law, UNSW Australia, Sydney, NSW 2052, Australia. Email: b.tran-nam@unsw.edu.au

${ }^{\dagger}$ This paper is derived from an Australian Research Council (ARC) Linkage project entitled "Assessing and addressing tax system complexity" with the Institute of Chartered Accountants in Australia (ICAA) (now Chartered Accountants Australia and New Zealand) as industry partner. The authors are also indebted to the Australian Taxation Office (ATO) for its invaluable assistance in conducting the research, and two anonymous referees for their helpful comments. The views expressed in this article are those of the authors and do not necessarily reflect the views of the ARC, ICAA or ATO. 


\begin{abstract}
The most recent, significant tax reform review in Australia, popularly known as the Henry Review, was publicly released just over six years ago. This article provides a critical examination of Australia's experience in tax complexity management since the Henry Review. Two main observations are put forward. First, not surprisingly, very few of the Henry Review's recommendations related to tax simplification have been implemented. The Henry Review has achieved relatively more with respect to personal income taxation than business income taxation. Second, tax complexity in Australia has been increasing since the Henry Review from both the legal and economic perspectives. An attempt is then made to explain why it is so hard to simplify the tax system in Australia and elsewhere.
\end{abstract}

\title{
1. Introduction
}

In analysing tax policy, economists tend to assume, at least implicitly, that tax administration and tax compliance are costless. This assumption, often invoked in the optimal taxation literature, conveniently allows economists to focus on the efficiency and equity implications of the taxes or tax system under study. The assumption, unrealistic as it is, may nevertheless be acceptable if tax operating costs (the sum of tax compliance and administrative costs) are either negligible or equal to a constant proportion of efficiency costs of all different kinds of taxes over time. Since neither of these conditions can be supported by empirical evidence, tax complexity ${ }^{1}$ cannot be disregarded in economic analyses of tax policy.

In reality, tax systems around the globe, especially in developed countries, have evolved into complex structures and Australia's system is not an exception. A substantial amount of

\footnotetext{
${ }^{1}$ For a detailed discussion on tax complexity, or its mirror tax simplicity, refer to Tran-Nam (2016). A distinction if often made between legal (structural) and effective complexity. Legal complexity refers to the difficulty with which a body of a tax law can be read, understood and applied in different practical situations. Effective complexity refers to the operating costs of a tax.
} 
evidence - anecdotal and empirical - suggests that the Australian tax system is highly complex both in absolute terms and relative to comparable tax systems (see, for example, Tran-Nam, Evans \& Lignier 2014; Lignier, Evans \& Tran-Nam 2014). Not surprisingly, ever since the Asprey Review (Asprey) in 1975, every single governmental tax reform proposal in Australia has consistently nominated tax simplification as a rationale for tax reform (for a detailed list of such proposals refer to Evans \& Tran-Nam 2010a, p. 441). Yet despite these repeated claims of simplification benefits from proposed tax changes, tax simplicity has remained as elusive as ever.

The most recent, significant tax reform proposal in Australia, the Review of Australia's Future Tax System (AFTS), popularly known as the Henry Review, was commissioned in May 2008 (AFTS Review Panel 2008) and publicly released in May 2010 (Australian Government 2010). Tax simplification or, more accurately, tax complexity management, featured prominently in the Henry Review. While tax simplification takes time to be implemented, the passage of time since the release of the Henry Review seems to be just sufficiently long to permit a preliminary assessment of the success, or otherwise, of the Henry Review from the tax simplicity perspective. To this end, this paper aims to provide a critical examination of Australia's experience in tax complexity management since the Henry Review. $^{2}$

The remainder of this article is structured as follows. The next section presents an overview of key issues on tax complexity that have emerged from the Henry Review. Given the wide-ranging scope of tax complexity only a few major issues are focused upon. Section 3 discusses how these issues have been addressed or why they have not yet been addressed.

\footnotetext{
${ }^{2}$ Note that the article restricts itself to an analysis of the position in the period to date. Deliberately, it does not attempt to evaluate whether further recommendations emanating from the Henry Review may or may not be implemented in the future. Such forward projections would require economic data and analysis which are beyond the scope of the article.
} 
It is apparent that most of the Henry recommendations on tax simplification have not yet been implemented. Section 4 considers the structural causes of complexity and Section 5 looks at measurements of tax compliance costs in Australia. The findings derive from research conducted by the authors in the course of an ARC Linkage Project on assessing and addressing tax complexity. Section 6 discusses why is hard to achieve meaningful tax simplification and sketches out a few ideas on how tax complexity can be managed in Australia. Section 7 concludes.

\section{Henry Review and Tax Complexity}

As suggested previously, tax complexity management was viewed as a key rationale for tax reform in the Henry Review. The Terms of Reference of the Henry Review made direct reference to this goal in four of the nine objectives laid down for the Henry Review Panel. These included that the Henry Review should:

- "...minimise complexity for taxpayers and the community";

- consider "...simplifying the tax system, including consideration of appropriate administrative arrangements across the Australian Federation";

- "ensure there are appropriate incentives for...reducing tax system complexity and compliance costs"; and

- "take into account the relationships of the tax system with the transfer payments system...with a view to ... reducing complexity and maintaining cohesion" (Australian Government 2010, pp. vii-viii). 
This early focus on simplification was maintained during the Henry Review's deliberations. In the Architecture of Australia's Tax and Transfer System paper prepared for the Henry Review, the Australian Treasury devoted a full chapter to complexity and the operating costs of the tax-transfer system (Australian Treasury 2008, pp. 305-321). Further, in the subsequent Consultation Paper (AFTS Review Panel 2008), the words simplicity and complexity were mentioned as often as fairness/equity/inequity and efficiency/inefficiency together combined. Throughout 280 pages of the Consultation Paper, the Henry Review Panel mentioned "simplicity and complexity" 229 times, compared to 110 mentions of "fairness and equity/inequity" and 120 for "efficiency/inefficiency" (Kerr 2010).

The Henry Review itself maintains this strong focus on simplification. Its vision of a 21 st century tax and transfer system includes, significantly, reforms to "exploit opportunities to reduce compliance costs and make interactions with the tax and transfer system easier, more certain and more understandable" (Australian Government 2008, p. xvii). This emphasis continues throughout the two volumes of Detailed Analysis contained in the AFTS Report (2008). A consistent theme in both the final report of the Henry Review and its earlier publications is the importance of simplifying the tax system and encouraging a more citizencentric design to the way that the tax system mediates the interaction between taxpayers and the agencies of government. Some of its key messages on managing tax complexity will be restated below.

Recognising the need for tax simplification, the Henry Review notes that "Australia has too many taxes and too many complicated ways of delivering multiple policy objectives through the tax and transfer systems" and suggests that "rationalisation of the tax and transfer architecture should now be a strategic priority" (Australian Government 2008, p. xvii). The causes of tax complexity are identified by the Henry Review as a result of "the pursuit of 
finely calibrated equity and efficiency outcomes, instability in policy settings and people's incentives to maximise their after-tax and transfer incomes or after-tax business profits" (Australian Government 2008, p. 21). The Henry Review also expresses concerns about the adverse effects of tax complexity, including high tax collection costs, reduced transparency, impediments to optimal economic behaviour, unintentional non-compliance and regressive impact (Australian Government 2008, p. 21).

Later the Henry Review notes that "personal tax compliance has become inordinately complex....An opportunity exists to greatly simplify personal tax, to make its policy more transparent, and to use 21st century technologies to make it fairer, easier to comply with and more robust" (AFTS Review Panel 2009, Pt 1, p. xix) and that "small businesses bear a disproportionally higher share of the tax compliance burden. To reduce this burden and to provide small business with greater tax certainty, the existing small business tax concessions should be streamlined and broadened" (AFTS Review Panel 2009, Pt 1, p. 41).

While the government stated that the GST was beyond the scope of the Henry Review, the high and visible business costs of complying with the GST, especially those incurred by small businesses, do not escape the attention of the Henry Review. It suggested the GST "is an operationally complex tax, designed on tax invoice concepts more suited to the documentary standards of the 1960s than the digital potential of the 21 st century" (AFTS Review Panel 2009, Pt 1, p.xxi).

In terms of tax administration the Henry Review expresses its dissatisfaction with taxpayer experience by claiming that "[c]urrently, people's interactions with the tax and transfer system tend to be complex and fragmented" (AFTS Review Panel 2009, Pt 1, p. 71). There is accordingly a specific section dealing at length with ensuring an improved client experience of the tax and transfer system (AFTS Review Panel 2009, Pt 2, Vol. 2, pp. 697-705). 
In addition to detailed analysis, the Henry Review included a large number of recommendations - some specific and some more general - relating to the way in which the tax and transfer systems in Australia might be made less complex over the 40 year timeframe adopted by the Henry Review. Indeed, of its 138 recommendations, roughly one quarter specifically mention simplicity/complexity or have an obvious impact on the simplicity/complexity of the tax system.

The Henry Review suggested in its first recommendation (AFTS Review Panel 2009, Pt 1, p. 25) that "revenue raising should be concentrated on four robust and efficient broad-based taxes:

- personal income, assessed on a more comprehensive basis;

- business income, designed to support economic growth;

- rents on natural resources and land; and

- private consumption".

Focusing on personal income taxation the relevant recommendations (in descending order) are concerned with:

- a high tax-free threshold with a constant marginal rate for most people (Recommendation 2);

- exemption from tax of income support and supplementary payments (Recommendation 4);

- elimination of the Medicare levy (Recommendation 5);

- removal of most concessional offsets (Recommendation 6);

- removal of the private health insurance rebate from the tax system by its conversion to a premium reduction (Recommendation 7(b)); 
- a standard deduction for Work Related Expenses (WRE) and tax agent expenses (and a claims threshold) (Recommendation 11);

- tightening the nexus between expense deductibility and its role in producing income (with a view to reducing the incidence of claims) (Recommendation 12);

- raising of the gift deductibility threshold from \$2 to \$25 (Recommendation 13);

- the manner in which personal taxpayers interact with the capital gains tax (CGT) regime (Recommendation 17); and

- pre-population of personal income tax returns by the ATO with third party data.

Relevant recommendations that may simplify business income taxation include: ${ }^{3}$

- reducing the scope of fringe benefits that are subject to tax (Recommendation 9)

- replacing State payroll taxes with revenue from more efficient broad-based taxes that capture the value-add of labour (Recommendation 57);

- principles-based approach to tax law design as a way of addressing the growing volume and complexity of tax legislation (Recommendation 12);

- $\quad$ updating and rewriting trust rules (Recommendation 36);

- gradually mandatory electronic provision of tax related business data by third parties (Recommendation 125); and

- progressing the Standard Business Reporting (SBR) ${ }^{4}$ initiative (Recommendations 126,127 and 128).

\footnotetext{
${ }^{3}$ The recommendations are listed in the order of tax policy (Recommendations 9 and 57), tax law drafting (Recommendations 12 and 36) and tax administration (Recommendations 125-128).

${ }^{4}$ SBR intends to reduce the business reporting burden by standardising data collection and minimising duplication of reporting. In particular, it seeks to reduce the number of channels for business to government
} 
It can be seen that the Henry Review covers all aspects of tax simplification: policy, legislation and administration. For a more detailed analysis of the above recommendations the interested reader is referred to Evans and Tran-Nam (2010a).

By way of providing further context, two other countries with broadly comparable tax regimes - New Zealand and the United Kingdom (UK) - were subject to comprehensive reviews of their tax systems at roughly the same time as the Henry Review was taking place in Australia. In New Zealand the review was conducted by the Tax Working Group (2010) at Victoria University Wellington, whilst in the UK Sir James Mirrlees (2011) led a team assembled by the Institute for Fiscal Studies. As noted by Evans (2012), while "the three countries share many cultural, social, economic and political traditions and institutions, careful analysis suggest that this shared heritage does not necessarily extend to the realms of tax reviews and the possible roads to tax reform that the countries may tread." Indeed, there are rather more differences than similarities in both the processes and the outputs of the three reviews. Moreover, neither the Tax Working Group in New Zealand nor the Mirrlees Review in the UK provided anything like the same level of detail or paid anything like the same level of attention that was given in Australia by the Henry Review to the problems associated with managing tax system complexity. Hence little further consideration of these overseas reviews is undertaken in this article.

\section{Post-Henry Responses}

After the public release of the Henry Review on 2 May 2010, the ALP Federal Government offered an initial response in the form of a joint Media Release (Rudd \& Swan 2010) on the same day and in Budget announcements (Swan 2010) nine days later. While the Government

reporting as well as the volume of reporting from business to government and move towards a common data exchange language. 
expressed its support for a simpler tax system, "especially for small businesses through simpler tax arrangements" (Rudd \& Swan 2010, p. 1), it was apparent that tax simplification was of the lowest order in their priorities. The ALP Government's aim at that time was the introduction of the ill-fated Resource Super Profits Tax, which was later enacted as the Minerals Resource Rent Tax by the Gillard-led ALP Government in March 2012 (with effect from 1 July 2012) and subsequently repealed by the Abbott-led Coalition Government two and a half years later.

While the panel members of the Henry Review chose a timeframe of 40 years for the eventual adoption and implementation of their recommendations, the then ALP Federal Government indicated that it saw the Henry Review as the first step in the 10 year tax reform agenda. Not surprisingly, the Government of the day accepted or rejected only a small number of recommendations. It was silent on the majority of the Henry Review's recommendations, leaving room for uncertainty and speculation on many key tax areas. Virtually all of the Henry Review proposals that were accepted by Government at the time are unrelated to tax simplification.

The Henry Review's proposal on the pre-population of personal income tax returns with third party data largely accorded with developing practice of the ATO (see Evans \& TranNam 2010b). However, some of the recommendations relating to the creation of the fully automated pre-filling tax regime were ruled out by the Government of the day. It therefore remains to be seen how committed the present Coalition Government will be to the introduction of a fully automated pre-filling regime, particularly bearing in mind the interconnectedness of the various components required to implement such a regime. The signs thus far are not entirely promising. 
The Government also rejected other recommendations specifically related to tax simplification. For example, the Government unequivocally rejected any increase in the gift deductibility threshold and also ruled out the removal of some concessional offsets such as the overseas forces tax offset (Rudd \& Swan 2010).

Although the Government did not embrace the idea of a "flat" tax implied in Recommendation 2, the tax free threshold for individuals was significantly raised from $\$ 5,000$ in $2011-12$ to $\$ 18,200$ in $2012-13$. To date, the changes that have been adopted have had no impact on structural complexity. Nor is there any evidence that it has reduced tax compliance costs of individual taxpayers. For the rate changes to lead to simplification, wholesale changes are needed tax administration procedures such as automated assessments and removal of filing requirements for persons whose taxable income is pre-determined by the ATO. If these changes were adopted, many individual taxpayers with taxable incomes below the tax-free threshold might find it unnecessary to (i) keep work related deduction (WRD) records rigorously, and (ii) engage tax practitioners to assist them with income tax return preparation.

The Henry Review's Recommendation 11 to allow a standard WRD, accepted by the Government of the day in its Budget of 11 May 2010, did not go far enough. If the Henry Review Panel was truly committed to simplification it would have proposed removing WRDs entirely - perhaps to be accompanied by a compensatory reduction in headline tax rates for individual taxpayers. ${ }^{5}$ Potentially this could have helped lead the way to reduced annual filing. More importantly, it would yield immediate simplicity dividends for most personal taxpayers. But the Report recommendation as it stood would lead to a "worst of both worlds" outcome. Personal taxpayers would have the choice of either taking a standard WRD or

\footnotetext{
${ }^{5}$ Evans, Tran-Nam and Andrew (2007, p. 23) made such a proposal in their study of personal income tax (PIT) reform.
} 
opting to itemise and claim actual expenses. Faced with the choice of two methods, many taxpayers will seek to calculate the outcomes under both before choosing which to use. From a tax simplicity perspective, it is better not to offer a choice in such circumstances. Not surprisingly, the Treasury's proposal for a standard deduction for combined WRDs and the costs of managing tax affairs of individual taxpayers, due to be introduced from 1 July 2012, was subsequently abandoned due to lack of support by the community, tax practitioners and tax academics (Tran-Nam \& Evans 2011).

The Henry Review has been poorly received by the Coalition Federal Governments under the leadership of both Tony Abbott and Malcolm Turnbull. The Henry recommendations were largely set aside, with the Coalition Government embarking on its own tax reform program, releasing a tax discussion paper on what it called the "Re:think" initiative in March 2015 (Australian Government 2015) and seeking public submissions on tax issues. Again, tax simplification has been articulated as a key rationale for tax reform (Australian Government 2015, p. 2) with Complexity - a Sketch in Five Slides leading the publicity charge on the government's website devoted to the program. ${ }^{6}$

While the Re:think agenda adds no apparent value or new insights to the existing analysis and recommendations of the Henry Review generally, its emphasis on reducing tax complexity is notable. The promotion of simplicity over equity has raised concern in some quarters but overall there is an advancement of attention on tax complexity perspective with an explicit recognition of the need to monitor the level of tax complexity over time (Australian Government 2015, pp. 189-191). In this context, various approaches for measuring tax complexity have been discussed, including the tax complexity index being developed by the UK Office of Tax Simplification (OTS) (see Jones et al 2014) or the tax system complexity index being proposed by Tran-Nam and Evans (2014).

\footnotetext{
${ }^{6}$ See http://bettertax.gov.au/publications/multimedia/five-slides/ accessed 3 July 2016.
} 
The UK's OTS is currently in the process of being made into a permanent and statutory body, following positive assessments of its work by both the UK government and independent organisations. ${ }^{7}$ In addition to its work on the development of a complexity index, in its first five years (from 2010 to 2015) the OTS completed 10 tax simplification projects, published 32 reports and papers, and made 402 formal recommendations. The detailed reports are all available on its website. ${ }^{8}$

It will be very interesting to see how the new, permanent and expanded OTS performs over the next five years, and whether its beefed-up role gives it the confidence and clout to tackle the difficult areas it has shied away from in the past. It will also be very interesting to see whether, and how, countries such as Australia can learn from the experience of the OTS. Certainly, a case can be made for the introduction of such a body in Australia (Sherwood, Evans \& Tran-Nam 2016), although there are, as yet, no formal proposals for such a body in Australia.

\section{Structural Causes of Complexity and Post-Henry Non-Responses}

A number of structural causes of complexity, deriving from the legal language or legal design of the tax law, have been identified (Krever 1987; 2003).

A primary cause is the use of thresholds or classifications with poorly defined or undefined boundaries. The example that gives rise to considerable complexity and consequent rulings by the tax authority and litigation over disputed assessments is the distinction between business income and capital gains. Business income of individuals is fully taxed. Capital gains on assets held for a year or more are half exempt from taxation.

\footnotetext{
${ }^{7}$ See https://www.gov.uk/government/organisations/office-of-tax-simplification/about/our-governance accessed 3 July 2016.

${ }^{8}$ https://www.gov.uk/government/organisations/office-of-tax-simplification.
} 
The law is, however, silent on the distinction between capital gains and business income. To determine the character of a gain, taxpayers must consider the facts of their acquisition and disposal in light of the lines drawn in several hundred years of precedents that develop the judicial concepts of income and capital gains.

Providing a clear an unambiguous borderline between the two was an important recommendation of the Review of Business Taxation (RBT) 17 years ago (RBT 1999, p. 178). The RBT spelled out very specific gains that would qualify for capital gains treatment. The Henry Review a decade later called for "greater transparency about the policy objective of the tax laws [which] will support a purposive approach to interpretation" (AFTS Review Panel 2009, p. 660) and a clear definition of the boundary to reduce compliance costs (AFTS Review Panel 2009, p. 83). In 2016, taxpayers face a tax system that offers a 50 per cent exemption from taxation for an undefined category of income with no signal in the law of what attributes distinguish fully taxed from half taxed gains and no guidance that might shed light on any social, economic or political rationale for the concession to help taxpayers, tax administrators and tax adjudicators understand the intended boundaries of the concessionally taxed gains.

Another legal cause of complexity is the proliferation of spending programs embedded in the tax laws. Labelled tax expenditures in tax policy literature and recorded in an "annual tax expenditure statement" of indirect government expenditures, these are hundreds of concessions aimed at biasing taxpayers' decisions to consume, invest or conduct business in particular forms or ways. Measures such as full or partial exemptions, concessional deductions and concessional credits are adopted by a legislature that assumes it is in a better position than the undirected market to allocate private sector resources or to correct market failures. Often drafted too loosely, the concessions are inevitably exploited by taxpayers who recharacterise behaviour that would otherwise fall outside the likely intended scope of a 
concession so it qualifies for the subsidy, leading to a never-ending chain of complex amendments followed by a host of new schemes.

Curbing the use of tax expenditures was a key theme of the Henry Review, which suggested subsidy "programs should not be delivered as tax expenditures unless there is a clear countervailing benefit in terms of efficiency, equity, complexity, sustainability and policy consistency" (AFTS Review Panel 2009, p. 719). Transparency was the key concept in the Henry Review's views on tax expenditures: "Tax expenditures should ideally be subject to the same levels of transparency and accountability as equivalent spending programs" (AFTS Review Panel 2009, p. 725). The year of the Henry Review, tax expenditures were estimated to cost $\$ 113$ billion a year or around 8.8 per cent of GDP (Australian Treasury 2010, p. vii). Three years after the Henry Review, Treasury reversed its transparency policy and removed the total cost of identified tax expenditures from its annual tax expenditure statement (Australian Treasury 2013). At the same time, Australia had emerged perhaps the developed world's leader in terms of the spending programs through tax expenditures as a percentage of GDP (Tyson 2014).

A third structural cause of complexity is the provision of elections for taxpayers who are able to choose between multiple alternative, often concessional, rules. As the optimal choice can only be determined after the implications of each of the alternatives had been measured, compliance costs blow out by a factor of the number of options available. As many of the elections are available for smaller businesses, the higher compliance costs tend to be borne by small business.

An example is the vast array of concessions for small business adopted in the past decade and a half. Concessional rules for filing times, depreciation and write-offs, and a host of capital gains concessions are intended to subsidise investment in small business, seen as an 
important element of the economy and presumably thought to suffer some market failures in terms of access to capital or forced to bear relatively higher costs to comply with government regulations and obligations. As it turns out, most of the large concessions encourage exiting from the sector, not providing assistance with startup or ongoing support. Capital gains concessions include a " 15 year exemption", a " $50 \%$ reduction", a "retirement exemption" and a "small business rollover" measure. Some concessions have to be applied before other concessions (e.g., the 15 year exemption takes priority over the small business rollover), but in most other cases taxpayers can elect which concession they will use, which means all alternatives must be tested to make the optimal election.

\section{Changes in Tax Compliance Costs}

Due to the paucity of empirical data it is not possible to compare the tax compliance costs in Australia in 2010 and now. Nevertheless, there is evidence supporting the claim that tax compliance costs are increasing over time. Comparing two comparable empirical studies conducted by some of the authors on tax compliance costs of personal taxpayers in Australia (Evans et al. 1997; Tran-Nam, Evans \& Lignier 2014, p. 170), aggregate gross compliance costs as a percentage of tax revenue have grown from 5.22 in 1994-95 to 6.37 in 2011-12, or, as a percentage of GDP, from 0.44 in 1994 to 0.57 in 2011-12. Aggregate net tax compliance $\operatorname{costs}^{9}$ have similarly grown from 4.00 per cent to 4.84 per cent of tax revenue, or from 0.34 per cent to 0.43 per cent of GDP, during the same period.

Using average estimates of gross/net tax compliance costs per personal taxpayer, the growth in real costs (after adjusting for the changes in the price level) have also been

\footnotetext{
${ }^{9}$ Net tax compliance costs are equal to gross tax compliance costs minus offsetting compliance benefits to taxpayers (such as tax deductibility, cash flow benefits, or cash subsidies from government).
} 
substantial. The average real costs per taxpayer rose from $\$ 462 / \$ 349$ to $\$ 797 / \$ 605$, representing a growth rate of about 73 per cent from 1994-95 to 2011-12 for both measures (Tran-Nam, Evans \& Lignier 2014, p. 171). Looking at more disaggregated numerical results, there is some evidence that very high-income personal taxpayers have increased the amount of outsourcing of their tax obligations to tax professionals. Even if the findings are discounted to reflect the impact of continuing economic prosperity of Australia over the comparison period, the trend of rising tax compliance costs is an indication of increasing tax complexity, or more tax planning behaviour, or a combination of both.

The results derived from a companion study on tax compliance costs of small and medium enterprises (SMEs) also confirm the findings of previous research in Australia and elsewhere, namely, tax compliance costs are increasing over time. That study indicates that overall tax compliance costs for the SME sector have increased from an average of about $\$ 5,000$ per firm in 1994-95 to just over $\$ 11,000$ in 2012-12 (using 1995 prices), representing an increase of 118 per cent in constant dollar terms (Lignier, Evans \& Tran-Nam 2014, p. 247). The study also found that while the increase in internal tax compliance hours was only 6 per cent since 1995 (mitigated by the innovations such as computerised record-keeping and electronic lodgement), spending on external services more than doubled in constant dollar terms. Moreover, nearly half of the overall increase could have been attributable to the introduction of the GST in $2000,{ }^{10}$ with increased legislative complexity and greater demands imposed on firms by the tax authority accounting for much of the balance.

\footnotetext{
${ }^{10}$ In fact, for SMEs, the GST has surpassed income tax as the single most expensive tax to comply with (Lignier, Evans and Tran-Nam 2014, pp. 237-239).
} 


\section{Why Is Tax Simplification so Difficult?}

Given that the causes and costs of tax complexity are more or less well known among tax academics, practitioners, administrators and policy-makers, it is somewhat puzzling that genuine tax simplification is so hard to achieve, not only in Australia but also elsewhere, especially in the developed world.

Before proceeding, it seems helpful to distinguish between necessary and unnecessary complexity (see, for example, Evans \& Tran-Nam 2010b; Ulph 2013). Necessary complexity refers to the minimum complexity required to achieve policy intention to an acceptable extent. Unnecessary complexity refers the excess of actual complexity over necessary complexity, such as overtly complex legislation, duplicated processes or excessively complicated tax forms. In this context, unnecessary complexity is not only unavoidable but also desirable (Evans \& Tran-Nam 2010b, p. 253)) whereas unnecessary complexity should be minimised as far as practicable.

To be sure, there are constitutional, institutional and policy constraints that limit the scope of tax simplification. The federal structure of government in Australia necessarily implies that there are many taxes. Policy makers will continue to succumb to the temptation of using taxes as tools of social and economic policy. Tax planners will continue to seek out and exploit opportunities in tax laws. Even with these constraints, however, some simplification measures should be feasible, in principle at least.

Successful tax reforms need champions. Successful tax simplifications also need champions. But why have politicians been shown to be much more reluctant to be true champions of tax simplification? It is perhaps that the serious costs of tax complexity have not yet penetrated the consciousness of political leaders. As a result, they continue to focus 
on issues of higher priority such as revenue raising or efficiency, and only pay lip service to the need for tax simplification.

This somewhat pessimistic conclusion about the lack of political engagement or "buy-in" so far as simplification in Australia is concerned may also be evident in the recent tax reform experience in New Zealand. As previously indicated, tax simplification was not a first order consideration in the formation of the Tax Working Group in New Zealand. Rather, its provenance may be accounted for by the interplay of somewhat ad hoc and accidental forces. The speakers at an international conference on tax policy held in February 2009 at the Victoria University of Wellington "identified significant concerns with the efficiency, equity and integrity of the current taxation system, concerns that required urgent attention" (Tax Working Group 2010, p. 5). "The support (and presence at the conference) of the New Zealand Inland Revenue and Treasury led to the formation of the review panel a few months later" (Evans 2012, p. 154).

In similar vein, the principal drivers which led to the establishment of the Mirrlees Review in the UK were not concerned with simplification per se, but rather with establishing a more efficient and equitable tax system, captured in the phrase that became the "core - though not the entirety - of [the Mirrlees] proposal...”: “...a progressive, neutral tax system” (Mirrlees 2011, p. 472). To the extent that any political engagement with simplification in the UK has occurred, it has been through the development of the role of the OTS, and not through the reform process initiated by the Mirrlees Review.

It is also possible that, while tax complexity has many undesirable effects, major stakeholders of a tax system may not be supportive of tax simplification without conditions. That is, simplification efforts may not be possible without compensation for those who stand 
to lose (at least in the short run) from a simpler tax system. The interests of six groups need to be considered.

The first group comprises those taxpayers (personal and business) who consider that they benefit from tax complexity. More particularly such taxpayers take the view that they are better off maintaining complex concessions even when confronted with the possibility of lower tax rates if the concessions were removed. In the case of personal taxpayers, this is known as the "tax refund" culture. A taxpayer survey found that the majority of taxpayers considered the PIT system to be not simple yet they also objected to the proposal of replacing current WRD with a flat $\$ 300$ annual tax credit (Evans, Tran-Nam \& Andrew 2007, pp. 41, 44). Similarly, the Business Tax Working Group tax reform deliberations in 2012, for example, identified potential benefits from a cut to the company tax rate but noted that a consensus could not be found among the business community for offsetting base-broadening measures (Business Tax Working Group 2012, p. 14). Simplicity was one of the core principles developed by the Working Group (Business Tax Working Group 2012, p. 17). This experience certainly seems to echo the comments in Shaviro (2008, p. 124), that "[o]nce we get beyond slogans, however, [tax] simplification is a public good that few political actors value more than the opportunity to shift their own tax burdens to someone else".

The second group comprises tax practitioners who spend a large part of their chargeable hours on personal and business tax returns. It was found that while 76 per cent of tax practitioners regarded the PIT system as being not simple, 67 per cent opposed the WRD simplification proposal compared with 27 per cent who supported it (Evans, Tran-Nam \& Andrew 2007, pp. 42 \& 44).

The third group comprises high-income personal taxpayers and large corporations able to exploit loopholes arising from complexity to avoid tax. Further, empirical studies of tax 
compliance costs of personal taxpayers in Australia suggest that high-income taxpayers derive cash flow benefits whereas low-income taxpayers tend to suffer cash flow costs from tax compliance (Tran-Nam, Evans \& Lignier 2014, p. 156). These matter because highincome or high-wealth individuals tend to be better organised in terms of political lobbying.

The fourth group comprises business and welfare organisations in Australia that, like personal taxpayers, may also be more interested in shifting tax burdens to other taxpayers than in reducing overall tax complexity.

A similar situation may exist (but to a lesser extent) with the fifth group consisting of some tax administrators who may see tax complexity as a protection of revenue collection or their own positions or number of staff members in their units.

The sixth group comprises politicians who perceive opportunities for political gains through targeted tax expenditures that may raise overall compliance and administrative costs but deliver substantial after-tax and compliance benefits to preferred constituents or achieve distortions in the economy that are viewed as beneficial by political policy-makers.

Given the above vested interests in tax complexity by a range of stakeholders, it is not surprising that tax policy-makers are not too willing to tackle the sensitive issue of tax simplification. But if the government is genuinely willing to simplify the tax system, what kind of tax simplification is most likely to succeed? In other words, what is the simplification potential of tax policy, statutory and administrative reforms?

It is apparent that tax rule changes arising from policy reforms can generate tremendous simplification impact. Replacing piecemeal ad hoc measures with clear principles and unambiguous fallback rules can reduce complexity (Krever, 2008). However, redrafting an existing tax law using different language but retaining the same policies has limited 
beneficial effects on tax complexity as the unfinished task of redrafting the income tax law in "plain English" and removing inoperative provisions have shown (Tran-Nam 2016). Simplification means changing the effect of the law, not the words in the law.

From a tax policy perspective, simplification may be achieved by considering, for example, the choice of the tax base (e.g., narrow-based with many boundaries versus broadbased taxes with few boundaries), the choice of policy instruments (e.g., direct subsidy versus use of the tax system), and whether or not to provide choices to taxpayers (e.g., multiple optional small business concessions). In the face of such a wide range of groups with vested interests in maintaining complexity, such reforms are difficult to achieve.

It is possible to make positive changes within the geo-political constraints, however. From the administrative perspective, simplification can be achieved through cultivation of a more cooperative tax culture, ${ }^{11}$ greater coordination with non-tax reporting (e.g., SBR: see Zakowska 2010), reduction of administrative requirements (e.g., reduced annual filing or reduced frequency of tax reporting), and easier completion and lodgement of income tax returns/business activity statements (e.g., e-tax, pre-filled income tax returns). In Australia administrative simplification is most likely to be achievable and have the greatest impact. This partly reflects the strength and ability of the ATO in implementing administrative reforms.

\section{Summary Conclusion}

The Henry Review is a very (if not the most) comprehensive, significant and ambitious tax reform study in Australia to date. The Henry Review panel members were very wise in

\footnotetext{
${ }^{11}$ As, for example, in New Zealand where it has been argued that the generic tax policy process has led to the cultivation of a more cooperative tax culture: see Sawyer (2013).
} 
choosing a very long timeframe of 40 years for the adoption and implementation of their recommendations. In 2050, very few of the present tax researchers and possibly none of the Henry Review Panel members will be around to consider the ultimate impact of the Henry Review on the Australian tax system. While it may be somewhat premature to assess the impact of the Henry Review on tax simplification, the signs have not been promising so far. Very few of the Henry Review's genuine recommendations have been successfully adopted or implemented by the federal government of either side of politics. Despite its obvious values and contributions, the Henry Review runs the danger of being rendered obsolete or less relevant by the Tax White Paper released in March 2015 (Australian Government 2015) and future tax reform proposals that are more consistent with changing international and domestic economic conditions. At the same time, it is also apparent that tax system complexity in Australia, however measured, continues to increase, and that there is no realistic prospect of any significant reduction in complexity for the foreseeable future.

\section{References}

Asprey, K. (1975), Taxation Review Committee, Full Report (Canberra: AGPS).

Australia's Future Tax System Review Panel (Dr K Henry, chair) (2008), Australia's Future

Tax System Consultation Paper (Canberra: Commonwealth of Australia).

Australia's Future Tax System Review Panel (Dr K Henry, chair) (2009), Australia's Future Tax System - Report to the Treasurer (Canberra: Commonwealth of Australia) (Henry Review).

Australian Government (2010), Stronger, Fairer, Simpler: A Tax Plan for Our Future (Canberra: Commonwealth of Australia). 
Australian Government (2015), Re:think Tax Discussion Paper (Canberra: Commonwealth of Australia) http://bettertax.gov.au/files/2015/03/TWP_combined-online.pdf

Australian Treasury (2008), Architecture of Australia's Future Tax System (Canberra: Commonwealth of Australia).

Australian Treasury (2010), Tax Expenditure Statement (Canberra: Commonwealth of Australia).

Australian Treasury (2013), Tax Expenditure Statement (Canberra: Commonwealth of Australia).

Business Tax Working Group (2012), Final Report, 1 November (Canberra: Commonwealth of Australia).

Evans, C. (2011) "Reflections on the Mirrlees Review: An Australasian Perspective", Fiscal Studies, 32(3), pp. 375-393.

Evans, C. (2012) "Reviewing the Reviews: A Comparison of Recent Tax Reviews in Australia, the United Kingdom and New Zealand”, Journal of Australian Taxation, 14(2), pp. 146-182.

Evans, C., K. Ritchie, B. Tran-Nam and M. Walpole (1997), A Report into Taxpayer Costs of Compliance (Canberra: Australian Government Publishing Service).

Evans, C., B. Tran-Nam and B. Andrew (2007), “Towards Systemic Reform of the Australian Personal Income Tax: Developing a Sustainable Model for the Future", Australian Tax Forum, 22, pp. 15-47. 
Evans, C. and B. Tran-Nam (2010a), “Controlling Tax Complexity: Rhetoric or Reality?”, in C. Evans, R. Krever and P. Mellor (eds), Australia's Future Tax System: The Prospects After Henry (Sydney: Thomson), pp. 437-461.

Evans, C. and B. Tran-Nam (2010b), "Managing Tax System Complexity: Building Bridges through Pre-filled Tax Returns", Australian Tax Forum, 25, pp. 245-274.

Jones, G., P. Rice, J. Sherwood and J. Whiting (2014), Developing a Tax Complexity Index for the UK (London: Office of Tax Simplification) https://www.gov.uk/government/uploads/system/uploads/attachment_data/file/285944/O $\underline{\text { TS_Developing_a_Tax_Complexity_Index for the_UK.pdf }}$

Kerr, J. (2010), "The Bridge to No Return: The Need for Simplification versus the 'Refund Culture?", in K. Datt, B. Tran-Nam and K. Bain (eds), International Tax Administration: Building Bridges (Sydney: CCH), pp. 173-195.

Krever, R. (1987), “Avoidance, Evasion and Reform: Who Dismantled and Who's Rebuilding the Australian Income Tax System?", University of New South Wales Law Journal, 10, pp. 215-240.

Krever, R. (2003), “Taming Complexity in Australian Income Tax”, Sydney Law Review, 25, pp. $467-505$.

Krever, R. (2008), “Plain English Drafting, Purposive Drafting, Principle-based Drafting: Does any of it Matter?"” in J. Freedman (ed.), Beyond Boundaries: Developing Approaches to Tax Avoidance and Tax Risk Management (Oxford: Oxford University Centre for Business Taxation), pp. 189-195. 
Lignier, P., C. Evans and B. Tran-Nam (2014), "Tangled Up in Tape: The Continuing Tax Compliance Plight of the Small and Medium Enterprise Business Sector", Australian Tax Forum, 29, pp. 217-247.

Mirrlees, J. (2011), Tax by Design: The Mirrlees Review (London: Institute for Fiscal Studies).

Review of Business Taxation (1999), A Tax System Redesigned - More Certain, Equitable and Durable (Canberra: Commonwealth of Australia).

Rudd, Hon. K. (Prime Minister) and Hon. W. Swan (Treasurer) (2010), "Stronger, Fairer, Simpler: A Tax Plan for Our Future," Media Release, 2 May.

Sawyer, A. (2013), "Reviewing Tax Policy Development in New Zealand: Lessons from a Delicate Balancing of Law and Politics”, Australian Tax Forum, 28, pp. 401-425.

Shaviro, D. (2008), “Simplifying Assumptions: How Might the Politics of Consumption Tax Reform Affect (Impair) the End Product?", in J.W. Diamond and G.R. Zodrow (eds), Fundamental Tax Reform: Issues, Choices, and Implications (Cambridge, MA: MIT Press), pp. $75-124$.

Sherwood, J., C. Evans and B. Tran-Nam (2016), "The Office of Tax Simplification: The Way Forward?", UNSW Australia mimeo.

Swan, W. (Treasurer) (2010), Budget Speech 2010-11, 11 May.

Tax Working Group (2010), A Tax System for New Zealand's Future: Report of the Victoria University of Wellington Tax Working Group (Wellington: Centre for Accounting, Governance and Taxation Research, Victoria University of Wellington). 
Tran-Nam, B. (2016), "Tax Reform and Tax Simplification: Conceptual and Measurement Issues and Australian Experiences", in S. James, A. Sawyer and T. Budak (eds), The Complexities of Tax Simplification: Experiences From Around the World (Basingstoke: Palgrave Macmillan), pp. 11-44.

Tran-Nam, B. and C. Evans (2011), "Tax Policy Simplification: An Evaluation of the Proposal for a Standard Deduction for Work Related Expenses", Australian Tax Forum, 26, pp. 719-735.

Tran-Nam, B. and C. Evans (2014), "Towards the Development of a Tax System Complexity Index", Fiscal Studies, 35, pp. 341-370.

Tran-Nam, B., C. Evans and P. Lignier (2014), "Personal Taxpayer Compliance Costs: Recent Evidence from Australia”, Australian Tax Forum, 29, pp. 135-170.

Tyson, J. (2014), “Reforming Tax Expenditures in Italy: What, Why, and How?", IMF Working Paper No. WP/14/7 (Washington, DC: International Monetary Fund).

Ulph, D. (2013), Measuring Tax Complexity, London: Office of Tax Simplification https://www.gov.uk/government/uploads/system/uploads/attachment_data/file/193497/ot s_david_ulph_measuring_tax_complexity.pdf

Zakowska, H. (2010), "Standard Business Reporting: A Bridge of Hope or the Bridge of Sighs?”, in K. Datt, B. Tran-Nam and K. Bain (eds), International Tax Administration: Building Bridges (Sydney: CCH), pp. 196-221. 